\title{
Plantas medicinais de uso popular em Boa Vista, Roraima, Brasil.
}

\author{
Francisco Joaci F. Luz \\ Embrapa Roraima; BR. 174, km 08, Distrito Industrial, C. Postal 133, 69.301-970, Boa Vista - RR. E-mail: joaci@cpafrr.embrapa.br
}

\section{RESUMO}

Boa Vista, capital do Estado de Roraima é composta de uma população muito heterogênea, compreendida por nordestinos, sulistas e amazônidas, que apresentam o hábito da utilização de plantas medicinais em suas manifestações culturais e costumes. Apesar do uso freqüente, as plantas medicinais apresentam cultivo muito incipiente, restringindo-se a canteiros de fundo de quintal e ao cultivo de subsistência em pequenas hortas comerciais. Este trabalho objetivou levantar e identificar as plantas medicinais de uso popular utilizadas em Boa Vista, por meio de informações obtidas com raizeiros, produtores de hortaliças e participantes em curso de plantas medicinais realizado pela Prefeitura Municipal. O trabalho foi realizado de janeiro de 1995 a abril de 1997, e constou de levantamento de informações sobre as plantas e seus usos, coleta de material e sua identificação botânica. Foram identificadas 60 famílias, das quais 8 espécies foram caracterizadas a nível de gênero e 105 a nível de espécie. Dentre as plantas medicinais citadas, foram relacionadas 14 hortaliças, 19 fruteiras, 9 consideradas plantas daninhas, 4 de lavoura, 26 de uso medicinal introduzidas de outras regiões e 41 de ocorrência natural em Roraima. A combinação de plantas medicinais nativas e exóticas, hortaliças, fruteiras e outras plantas cultivadas, no elenco das plantas medicamentosas de uso popular em Boa Vista caracteriza a diversidade de costumes e cultura próprios de uma população de origens diversas, refletindo a riqueza e o potencial do conhecimento popular na solução dos problemas de saúde da população local.

\section{ABSTRACT}

Medicinal plants of popular use in Boa Vista, Roraima, Brazil.

Boa Vista is located in the North of Amazonia, Brazil. The population of Boa Vista is heterogeneous, composed of Northeastern, Southern and Amazonian people. It has a strong tradition of using plants in popular medicine. This work aims to identify medicinal plants of popular use in Boa Vista, through information obtained from, horticulturists and participants in a medicinal plant course. The survey, made between January 1995 and April 1997, consisted of identifying plants and their use in popular medicine. Sixty families were identified of which genus and 105 by species name, were listed. Common vegetables, fruits, weed and cultivated crops were found among exotic and native medicinal plants. This combination of different species in the spectrum of medicinal plants of popular use in Boa Vista follows the diversity of habits and culture of people with different origins, with implications on the richness and potential use of popular knowledge in the cure of health problems.

\section{(Aceito para publicação em 23 de janeiro de 2.001)}

s plantas medicinais e suas formas

derivadas constituíram durante séculos a base da terapêutica (Scheffer, 1992). Aos poucos, com a evolução da química, substituíram-se os compostos naturais por quimioterápicos, que têm um elevado custo até a fabricação em escala e exigem um alto nível tecnológico para sua produção. Atualmente, as plantas medicinais passaram a ser cogitadas como recurso terapêutico viável, devido aos altos preços e à falta de acesso aos quimioterápicos por grande parcela da população.

No Nordeste brasileiro, cerca de 500 espécies vegetais, cuja maioria está cons- tituída de plantas silvestres, são usadas como medicinais, especialmente pela população do meio rural e da periferia urbana (Matos \& Bezerra, 1993).

Boa Vista, capital do Estado de Roraima localiza-se na parte Norte do Estado, apresenta vegetação de savana (Brasil, 1975), com fisionomia típica de 
cerrado. A população da cidade, em torno de 150.000 habitantes, é bastante heterogênea, sendo compreendida essencialmente de roraimenses, incluindo índios e descendentes dos pioneiros da colonização do Estado, sulistas, nordestinos e nortistas em menor número.

Essa heterogeneidade se reflete na diversidade das manifestações culturais e dos costumes da população boavistense. Dentre esses costumes, destaca-se o uso popular de plantas na cura das diversas enfermidades que atingem a população. Raizeiros e curandeiros, que trazem sua experiência na bagagem quando migram, e populações autóctones ainda mantêm o uso de plantas medicinais como alternativa fitoterápica, tal qual seus ancestrais. $\mathrm{O}$ cultivo de plantas medicinais em Boa Vista é muito incipiente, restringindose a canteiros de fundo de quintal e ao cultivo de subsistência em pequenas hortas comerciais, que produzem olerícolas de consumo popular. Muitas plantas medicinais são extraídas diretamente da natureza.

Correia Júnior et al. (1994) ressaltaram que, na medicina, produtos originários de plantas ocupam um espaço cada vez maior na terapêutica. No entanto, a coleta desenfreada de plantas nativas pode levar à extinção de espécies importantes.

A identificação e as informação obtidas sobre o uso de plantas medicinais podem ser utilizadas para orientar pesquisas com a finalidade de refinar ou otimizar os usos populares correntes, desenvolvendo preparados terapêuticos de baixo custo, ou isolar substâncias ativas passíveis de síntese pela indústria farmacêutica (Amorozo, 1996). Este trabalho objetivou levantar e identificar as plantas medicinais de uso popular utilizadas em Boa Vista.

\section{MATERIAL E MÉTODOS}

O trabalho foi realizado na cidade de Boa Vista, capital de Roraima, de janeiro de 1995 a abril de 1997. O mesmo constou de três fases, compreendendo levantamento e coleta de informações sobre as plantas e seu uso, coleta de material e identificação botânica.

O levantamento de plantas medicinais de uso popular em Boa Vista foi realizado por meio de questionário simplificado, constando o nome popular da planta, a parte utilizada, o uso e a condição de cultivo (subsistência ou comercial). Foram aplicados três questionários em duas feiras populares da cidade, a feira do produtor e o feirão dos garimpeiros, contemplando dois raizeiros, e em duas pequenas hortas comerciais da periferia da cidade. Ainda foram obtidos dados com quinze integrantes de um curso sobre plantas medicinais promovido pela Prefeitura Municipal de Boa Vista.

A coleta de material vegetal para identificação foi realizada em visitas a hortas e pomares caseiros. A identificação botânica foi feita na Embrapa Roraima. Foi realizada revisão bibliográfica para auxiliar na identificação botânica, sendo utilizadas as seguintes referências: Cruz, 1979; Lorenzi, 1991; Berg, 1993; Corrêa Júnior et al., 1994; Milliken, 1995; Carriconde et al., 1996; Mattos, 1996. Algumas plantas de difícil identificação a nível de espécie foram acondicionadas em excicatas, catalogadas e remetidas para identificação nos herbários da Universidade Federal de Roraima (UFRR) e do Museu Integrado de Roraima (MIRR).

\section{RESULTADOS E DISCUSSÃO}

Em relação às plantas coletadas, foram listadas 60 famílias, com 8 plantas identificadas a nível de gênero e 105 a nível de espécie. Os nomes científicos e populares, a parte da planta usada, a forma e as indicações de uso, estão relacionados na Tabela 1.

Dentre as plantas citadas, foram relacionadas 14 hortaliças, 19 fruteiras, 9 plantas consideradas ervas daninhas de plantas cultivadas (Lorenzi, 1991), 4 plantas de lavoura (arroz, milho, algodão e cana-de-açúcar), 26 plantas de uso medicinal introduzidas de outras regiões e 41 plantas de ocorrência natural em Roraima (Tabela 1). Essa diversidade na origem das plantas é fruto da heterogeneidade da população boavistense, composta de muitos migrantes, especialmente nordestinos. $\mathrm{O}$ grande número de plantas de ocorrência natural, decorre em parte da cultura indígena roraimense, com forte influência na cidade, onde existem bairros criados por índios que migraram para a cidade, assim como da influência dos amazônidas no uso de plantas da região.
Dentre as plantas medicinais introduzidas muitas são de uso comum no Nordeste (mastruço, coirama, hortelã, malvariço, quebra-pedra, cidreira, romã, etc), segundo Matos \& Bezerra (1993).

Foram citados mais de 70 tipos de doenças no levantamento. Os mais citados foram inflamações, gripe, diarréia, anemia, malária, diabete, doenças hepáticas e verminoses. Algumas doenças citadas são muito comuns em Boa Vista. Dentre as transmissíveis notificadas na cidade no ano de 1996, a malária destacou-se com $90 \%$ das ocorrências. Boa Vista também deteve $80,6 \%$ dos casos de diarréia notificados no Estado em 1996 (Pithan, 1996).

Os dois raizeiros consultados não residem em Boa Vista e adquirem seus produtos no interior do Estado. Um deles retira os mesmos diretamente da mata ou de uma pequena horta de plantas medicinais, trazendo mudas e cascas para comercializar. O outro especializou-se na venda de pequenos frascos de óleo de copaíba (Copaifera officinalis) e de andiroba (Carapa guianensis), retirados diretamente de árvores nativas da região do Quitauaú, em município vizinho a Boa Vista.

As hortas amostradas têm as plantas medicinais como complemento de renda das olerícolas ou mantêm o seu cultivo para uso próprio ou da comunidade próxima. O cultivo comercial nas hortas visitadas foi verificado apenas com a hortelã miúda (Mentha $x$ villosa $\mathrm{L}$.) que é comercializada para remédio e para condimento.

No curso de plantas medicinais patrocinado pela Prefeitura de Boa Vista foi relatado pelos participantes que o uso medicinal das plantas tinha origem na tradição familiar, passada por pais e avós. Não foi mencionado o cultivo comercial das plantas. Pequenas hortas de quintal e o cultivo em vasos mantinham o fornecimento de plantas para fins medicinais. Algumas plantas nativas, como caimbé (Curatella americana), mirixi (Byrsonima spp.), sucuba (Himathanthus articulatus), cajuí (Anacardium giganteum) e caçari (Myrciaria dubia) são exploradas diretamente da natureza, o que demonstra preocupação mencionada por Corrêa Júnior et al. (1994), quanto ao perigo da exploração desenfreada e à extinção de espécies ainda não cultivadas. 
Tabela 1. Plantas medicinais de uso popular no município de Boa Vista, Roraima. Boa Vista, Embrapa Roraima, 1997.

\begin{tabular}{|c|c|c|c|}
\hline Família/Nome científico & Nome popular & Parte e forma de uso & Uso medicinal \\
\hline \multicolumn{4}{|l|}{ Alliaceae } \\
\hline Allium cepa $L$. & Cebola & bulbo (xarope) & gripe; asma; expectorante \\
\hline Allium sativum $L$. & Alho & bulbilhos (chá) & $\begin{array}{l}\text { vermífugo; gripe; } \\
\text { inflamação na garganta }\end{array}$ \\
\hline \multicolumn{4}{|l|}{ Alismataceae } \\
\hline $\begin{array}{l}\text { Echinodorus grandiflorus } \\
\text { Mitch. }\end{array}$ & Chapéu-de-couro & folhas (chá) & tônico; antitussígeno \\
\hline \multicolumn{4}{|l|}{ Amaranthaceae } \\
\hline $\begin{array}{l}\text { Gomphrena globosa } L \text {. } \\
\text { Anacardiaceae }\end{array}$ & Perpétua; Perpetinha & flores (chá) & coração \\
\hline Anacardium occidentale $L$. & Caju & $\begin{array}{l}\text { casca (infusão) } \\
\text { pseudofruto (suco) } \\
\text { casca (infusão) }\end{array}$ & $\begin{array}{l}\text { antiinflamatório; } \\
\text { cicatrizante; antidiarréico } \\
\text { queimadura }\end{array}$ \\
\hline $\begin{array}{l}\text { Anacardium giganteum } \\
\text { Hancock ex Engler }\end{array}$ & Cajuí & folhas (chá) & antiinflamatório \\
\hline Mangifera indica $L$. & Manga & $\begin{array}{l}\text { fruta verde (xarope) } \\
\text { entre casca (chá) } \\
\text { folhas (chá) }\end{array}$ & $\begin{array}{l}\text { antitussígeno; gripe } \\
\text { inflamação na garganta } \\
\text { antidiarréico }\end{array}$ \\
\hline Spondias mombin L. & Taperebá; Cajá & casca (chá) fruto (suco) & $\begin{array}{l}\text { antiinflamatório; } \\
\text { cicatrizante; antidiarréico }\end{array}$ \\
\hline Astronium ulei Mattick & Aroeira & casca (chá) & antiinflamatório; asma \\
\hline \multicolumn{4}{|l|}{ Annonaceae } \\
\hline Anona muricata $L$. & Graviola & folhas (chá) & $\begin{array}{l}\text { diurético; digestivo; } \\
\text { obesidade }\end{array}$ \\
\hline \multirow[t]{2}{*}{ Anona squamosa $L$. } & Ata & folha (chá) & $\begin{array}{l}\text { fígado; rins; antidiarréico; } \\
\text { digestivo }\end{array}$ \\
\hline & & semente moída & vermífugo \\
\hline \multicolumn{4}{|l|}{ Apocynaceae } \\
\hline $\begin{array}{l}\text { Himathanthus articulatus } \\
\text { (Vahl) Woodson }\end{array}$ & Sucuba, Pau-de-leite & $\begin{array}{l}\text { casca (chá) } \\
\text { entrecasca (infusão) } \\
\text { latex }\end{array}$ & $\begin{array}{l}\text { malária; antiinflamatório; } \\
\text { inflamação ginecológica } \\
\text { leucemia }\end{array}$ \\
\hline $\begin{array}{l}\text { Aspidosperma nitidum } \\
\text { Benth. }\end{array}$ & Carapanauba & casca (chá) & $\begin{array}{l}\text { antiinflamatório; fígado; } \\
\text { malária; contraceptivo }\end{array}$ \\
\hline \multicolumn{4}{|l|}{ Bignoniaceae } \\
\hline $\begin{array}{l}\text { Adenocalymna aliaceum } \\
\text { Mart. }\end{array}$ & Cipó alho & folhas (infusão) & $\begin{array}{l}\text { gripe; banho infantil; } \\
\text { banho espiritual }\end{array}$ \\
\hline $\begin{array}{l}\text { Arrabidea chica (H.B.K.) } \\
\text { Verlot }\end{array}$ & Crajiru & folhas (chá) & $\begin{array}{l}\text { anemia; antiinflamatório; } \\
\text { cicatrizante }\end{array}$ \\
\hline $\begin{array}{l}\text { Tabebuia serratifolia (Vahl) } \\
\text { Nich. }\end{array}$ & $\begin{array}{l}\text { Pau d'arco amarelo; Ipê } \\
\text { amarelo }\end{array}$ & $\begin{array}{l}\text { casca } \\
\text { pó da madeira (chá) }\end{array}$ & $\begin{array}{l}\text { gastrite; úlcera } \\
\text { anemia; câncer }\end{array}$ \\
\hline \multicolumn{4}{|l|}{ Bixaceae } \\
\hline Bixa orellana $L$. & Urucum & $\begin{array}{l}\text { sementes trituradas; } \\
\text { raíz (chá) }\end{array}$ & $\begin{array}{l}\text { vitiligo } \\
\text { malária }\end{array}$ \\
\hline \multicolumn{4}{|l|}{ Boraginaceae } \\
\hline $\begin{array}{l}\text { Symphytum officinale } L \text {. } \\
\text { Borraginaceae }\end{array}$ & Confrei & folhas (chá) & cicatrizante; câncer \\
\hline Heliotropium indicum L. & Crista-de-galo & flor (infusão) & hipertensão \\
\hline
\end{tabular}


Tabela 1. (Continuação)

\begin{tabular}{|c|c|c|c|}
\hline Família/Nome científico & Nome popular & Parte e forma de uso & Uso medicinal \\
\hline \multicolumn{4}{|l|}{ Brassicaceae } \\
\hline Nasturtium officinale $R$. Br. & Agrião & folhas e flor (xarope) & antitussígeno; gripe \\
\hline $\begin{array}{l}\text { Brassica oleraceae } L . \\
\text { Bromeliaceae }\end{array}$ & Couve & folhas (suco) & gastrite; anemia \\
\hline Ananas comosus (L.) Meer. & Abacaxi & fruto (suco) & diurético \\
\hline \multicolumn{4}{|c|}{ Cactaceae } \\
\hline Cereus sp. & Mandacaru & $\begin{array}{l}\text { caule (infusão) } \\
\text { caule (chá) }\end{array}$ & $\begin{array}{l}\text { diabete } \\
\text { tuberculose; coqueluche; } \\
\text { pneumonia }\end{array}$ \\
\hline \multicolumn{4}{|l|}{ Caesalpinaceae } \\
\hline $\begin{array}{l}\text { Caesal pinia ferrea Mart. Ex } \\
\text { Tul. }\end{array}$ & Jucá & $\begin{array}{l}\text { vagem (chá); semente } \\
\text { (infusão) }\end{array}$ & $\begin{array}{l}\text { antiinflamatório; rins; } \\
\text { tuberculose; reumatismo; } \\
\text { limpeza de pele }\end{array}$ \\
\hline Copaifera officinalis Willd. & Copaiba & $\begin{array}{l}\text { casca (infusão) } \\
\text { entre casca (infusão) } \\
\text { óleo }\end{array}$ & $\begin{array}{l}\text { anemia } \\
\text { reumatismo } \\
\text { antiinflamatório; } \\
\text { cicatrizante; infecção na } \\
\text { garganta }\end{array}$ \\
\hline $\begin{array}{l}\text { Bauhinia rutilans Spruce } \\
\text { ex Benth. }\end{array}$ & $\begin{array}{l}\text { Escada-de-jaboti; Escada- } \\
\text { de-macaco }\end{array}$ & rama (chá) & analgésico \\
\hline $\begin{array}{l}\text { Bauhinia macrostachya } \\
\text { Benth. }\end{array}$ & Pata-de-vaca & folhas (chá) & diabete; colesterol \\
\hline Senna ocidentalis $(L$.$) Link$ & Fedegoso & raíz (chá) & hepatite; malária; diabete \\
\hline Hymenaea courbaril $L$. & Jatobá & $\begin{array}{l}\text { folha (chá) } \\
\text { fruto com semente } \\
\text { (macerado) } \\
\text { casca (chá) } \\
\text { entrecasca (chá) }\end{array}$ & $\begin{array}{l}\text { gripe; hemorróida; } \\
\text { diurético } \\
\text { tosse } \\
\text { tuberculose } \\
\text { anemia; gripe }\end{array}$ \\
\hline Cassia spruceana Benth. & Mari-mari & $\begin{array}{l}\text { folhas novas (infusão em } \\
\text { álcool) } \\
\text { folhas (suco) }\end{array}$ & $\begin{array}{l}\text { manchas da pele } \\
\text { antimicótico }\end{array}$ \\
\hline \multicolumn{4}{|l|}{ Caparidaceae } \\
\hline Tamarindus indica $L$. & Tamarindo & frutos e folhas (chá) & $\begin{array}{l}\text { antiinflamatório; diabete; } \\
\text { colesterol; antidiarréico; } \\
\text { obesidade }\end{array}$ \\
\hline \multicolumn{4}{|l|}{ Caprifoliaceae } \\
\hline $\begin{array}{l}\text { Sambucus nigra } L \text {. } \\
\text { Caricaceae }\end{array}$ & Sabugueiro & folhas e flor (chá) & sarampo; cachumba \\
\hline Carica papaya $L$. & Mamão & $\begin{array}{l}\text { folhas (xarope) } \\
\text { flor (chá) } \\
\text { fruto (in natura ou suco) }\end{array}$ & $\begin{array}{l}\text { gripe; antitussígeno } \\
\text { digestivo } \\
\text { laxante }\end{array}$ \\
\hline \multicolumn{4}{|l|}{ Celastraceae } \\
\hline Maytenus ilicifolia Reiss. & Espinheira santa & folhas (suco) & $\begin{array}{l}\text { gastrite; fígado; pedra nos } \\
\text { rins }\end{array}$ \\
\hline \multicolumn{4}{|l|}{ Chenopodiaceae } \\
\hline Beta vulgaris $L$. & Beterraba & folhas e raíz (suco) & anemia \\
\hline $\begin{array}{l}\text { Chenopodium } \\
\text { ambrosioides } L \text {. }\end{array}$ & Mastruço & $\begin{array}{l}\text { folhas, flores e frutos } \\
\text { (suco) }\end{array}$ & $\begin{array}{l}\text { gripe; vermífugo; } \\
\text { cicatrizante; tônico; } \\
\text { antiinflamatório; } \\
\text { vermífugo; tuberculose; } \\
\text { pneumonia }\end{array}$ \\
\hline
\end{tabular}


Tabela 1. (Continuação)

\begin{tabular}{|c|c|c|c|}
\hline Família/Nome científico & Nome popular & Parte e forma de uso & Uso medicinal \\
\hline \multicolumn{4}{|l|}{ Cichoriaceae } \\
\hline Lactuca sativa $L$. & Alface & folha (in natura); raíz (chá) & $\begin{array}{l}\text { calmante; digestivo; } \\
\text { insônia }\end{array}$ \\
\hline \multicolumn{4}{|l|}{ Compositae } \\
\hline Artemisia spp. & Artemísia; Cibalena & folhas (chá e banho) & antitérmico \\
\hline Ageratum conyzoides $L$. & $\begin{array}{l}\text { Mentastro; Eva-de-São } \\
\text { João }\end{array}$ & folhas; planta inteira & gripe \\
\hline Bidens pilosa $L$. & Picão preto & raíz (chá) & malária; hepatite \\
\hline Helianthus annus $L$. & Girassol & semente triturada & $\begin{array}{l}\text { sinusite; epilepsia; } \\
\text { meningite }\end{array}$ \\
\hline $\begin{array}{l}\text { Spilanthes oleracea }(L .) \\
\text { Jacq. }\end{array}$ & Jambu & folhas, flor e raíz (xarope) & antitussígeno; gripe \\
\hline \multicolumn{4}{|l|}{ Convolvulaceae } \\
\hline $\begin{array}{l}\text { Operculina alata (Ham.) } \\
\text { Urb. }\end{array}$ & Batata-de-purga & raíz & $\begin{array}{l}\text { depurativa do sangue; } \\
\text { laxante; antiinflamatório; } \\
\text { vermífugo }\end{array}$ \\
\hline \multicolumn{4}{|l|}{ Costaceae } \\
\hline Costus spp. & $\begin{array}{l}\text { Canafístula; cana-de- } \\
\text { macaco }\end{array}$ & ramos (chá) & diurético \\
\hline \multicolumn{4}{|l|}{ Crassulaceae } \\
\hline $\begin{array}{l}\text { Kalanchoe pinnata (Lam.) } \\
\text { Pers. }\end{array}$ & $\begin{array}{l}\text { Língua de Pirarucu; folha } \\
\text { santa; coirama }\end{array}$ & folhas (suco) & $\begin{array}{l}\text { antiinflamatório; dor de } \\
\text { ouvido }\end{array}$ \\
\hline \multicolumn{4}{|l|}{ Cucurbitaceae } \\
\hline Citrullus vulgaris Schrad. & Melancia & semente (chá) & diurético \\
\hline Cucumis anguria $L$. & Maxixe & fruto in natura & diabete \\
\hline Cucurbita pepo $L$. & Abóbora & semente & vermífuga \\
\hline $\begin{array}{l}\text { Luffa operculata (L.) Cogn. } \\
\text { In Mart. }\end{array}$ & Cabacinha & fruto(chá) & $\begin{array}{l}\text { sinusite; dor de cabeça } \\
\text { (inalação); abortivo }\end{array}$ \\
\hline \multicolumn{3}{|l|}{ Dilleniaceae } & antimicótico \\
\hline Curatella americana $L$. & Caimbé & entre casca (infusão) & $\begin{array}{l}\text { inflamação ginecológica; } \\
\text { diabete; câncer }\end{array}$ \\
\hline \multicolumn{4}{|l|}{ Euphorbiaceae } \\
\hline Croton cajucara Benth. & Sacaca & folhas e casca (chá) & $\begin{array}{l}\text { malária; hepatite; ressaca; } \\
\text { fígado }\end{array}$ \\
\hline Jatropha gossypifolia $L$. & Pinhão roxo & $\begin{array}{l}\text { folhas (infusão) } \\
\text { folhas } \\
\text { seiva }+ \text { água }\end{array}$ & $\begin{array}{l}\text { antitérmico } \\
\text { verruga; aftas } \\
\text { laxante }\end{array}$ \\
\hline Phyllanthus spp. & Quebra-pedra & $\begin{array}{l}\text { folhas, raíz e sementes } \\
\text { (chá) }\end{array}$ & diurético; cálculos renais \\
\hline \multicolumn{4}{|l|}{ Fabaceae } \\
\hline $\begin{array}{l}\text { Cajanus flavus De } \\
\text { Candolle }\end{array}$ & feijão andu; Guandu & folhas & sinusite; dor de cabeça \\
\hline $\begin{array}{l}\text { Desmodium adscendens } \\
\text { (Sw.) DC. }\end{array}$ & Carrapicho-beiço-de-boi & toda a planta & $\begin{array}{l}\text { doença venérea; asseio } \\
\text { vaginal }\end{array}$ \\
\hline
\end{tabular}


Tabela 1. (Continuação)

\begin{tabular}{|c|c|c|c|}
\hline Família/Nome científico & Nome popular & Parte e forma de uso & Uso medicinal \\
\hline \multicolumn{4}{|l|}{ Graminae } \\
\hline $\begin{array}{l}\text { Cymbopogon citratus D.C. } \\
\text { Stapf. }\end{array}$ & Capim santo & folhas(chá) & $\begin{array}{l}\text { analgésico; calmante; } \\
\text { antitérmico }\end{array}$ \\
\hline Oriza sativa $L$. & Arroz & $\begin{array}{l}\text { grão, casca e farelo } \\
\text { (caldo) }\end{array}$ & antidiarréico \\
\hline Saccarum officinale L. & Cana-de-açúcar & folhas (chá) & antihemorrágico \\
\hline Zea mays $\mathrm{L}$. & Milho & cabelo e palha (chá) & catapora; sarampo \\
\hline \multicolumn{4}{|l|}{ Iridaceae } \\
\hline \multirow[t]{2}{*}{$\begin{array}{l}\text { Eleutheriine bulbosa (Mill.) } \\
\text { Urban }\end{array}$} & Coquinho; Marupazinho & rizoma (infusão) & $\begin{array}{l}\text { antidiarréico; cólicas; } \\
\text { hemorróidas }\end{array}$ \\
\hline & & rizoma (chá) & inflamação na garganta \\
\hline \multicolumn{4}{|l|}{ Labiatae } \\
\hline Mentha pulegium $L$. & Poejo & folhas e ramas (chá) & gripe \\
\hline Mentha x villosa $L$. & Hortelã miúda & $\begin{array}{l}\text { folhas e ramos (chá, } \\
\text { xarope) }\end{array}$ & $\begin{array}{l}\text { verme; gripe; cólicas; } \\
\text { sinusite; antitérmico }\end{array}$ \\
\hline Ocimum spp. & Alfavaca & folhas (infusão) & $\begin{array}{l}\text { gripe; sinusite; catapora; } \\
\text { sarampo }\end{array}$ \\
\hline \multirow[t]{4}{*}{ Oncimum minimum L. } & Manjericão & folhas (infusão) & banho \\
\hline & & folhas (macerado) & dor de cabeça \\
\hline & & folhas (chá) & diarréia \\
\hline & & folhas (suco) & dor de ouvido \\
\hline \multirow[t]{2}{*}{$\begin{array}{l}\text { Plectranthus amboinicus } \\
\text { (Lour.) Spr. }\end{array}$} & $\begin{array}{l}\text { Hortelã-da-folha-grossa; } \\
\text { malvarisco }\end{array}$ & folhas (xarope) & gripe \\
\hline & & folhas (suco) & vermífugo \\
\hline $\begin{array}{l}\text { Plectranthus barbatus } \\
\text { Andr. }\end{array}$ & Boldo & folhas (infusão) & fígado; digestivo; ressaca \\
\hline \multicolumn{4}{|l|}{ Lauraceae } \\
\hline Persea gratissima Gaertn. & Abacate & $\begin{array}{l}\text { folhas e raíz (chá); } \\
\text { folhas, raíz, fruto e } \\
\text { semente (infusão) }\end{array}$ & $\begin{array}{l}\text { anemia; malária; fígado } \\
\text { rins; antiinflamatório }\end{array}$ \\
\hline \multicolumn{4}{|l|}{ Lecythidaceae } \\
\hline Bertoletia excelsa H.\&.B. & Castanha do Brasil & amêndoa (óleo) & hemorragia (uso externo) \\
\hline \multicolumn{4}{|l|}{ Liliaceae } \\
\hline \multirow[t]{2}{*}{ Aloe vera $L$. } & Babosa & folhas (chá) & digestivo; fígado \\
\hline & & folhas (suco) & $\begin{array}{l}\text { cicatrizante; antimicótico; } \\
\text { asma; queda de cabelo; } \\
\text { tumores; hemorróidas; } \\
\text { queimaduras }\end{array}$ \\
\hline \multicolumn{4}{|l|}{ Malpighiaceae } \\
\hline $\begin{array}{l}\text { Byrsonima crassifolia (L.) } \\
\text { H.B.K. }\end{array}$ & Murici & entre casca (chá) & $\begin{array}{l}\text { antidiarréico; } \\
\text { antinflamatório; malária }\end{array}$ \\
\hline $\begin{array}{l}\text { Byrsonima verbascifolia } \\
\text { (L.) Rich }\end{array}$ & $\begin{array}{l}\text { Murici de raposa; Orelha } \\
\text { de burro }\end{array}$ & raíz (chá) & antinflamatório; fígado \\
\hline Malpighia glabra L. & Acerola & fruto (suco) & gripe; anemia \\
\hline
\end{tabular}


Tabela 1. (Continuação)

\begin{tabular}{|c|c|c|c|}
\hline Família/Nome científico & Nome popular & Parte e forma de uso & Uso medicinal \\
\hline \multicolumn{4}{|l|}{ Malvaceae } \\
\hline Abelmoschus esculentum $L$. & Quiabo & semente (pó) & cansaço; asma \\
\hline Gossypium barbadense $L$. & Algodão & folhas e botão floral (chá) & $\begin{array}{l}\text { antiinflamatório; } \\
\text { antitussígeno }\end{array}$ \\
\hline Hibiscus sabdariffa $L$. & Vinagreira & folhas (cataplasma) & antimicótico \\
\hline \multicolumn{4}{|l|}{ Meliaceae } \\
\hline Carapa guianensis Aubl. & Andiroba & sementes (óleo) & $\begin{array}{l}\text { antiinflamatório; } \\
\text { cicatrizante }\end{array}$ \\
\hline \multicolumn{4}{|l|}{ Mimosaceae } \\
\hline $\begin{array}{l}\text { Piptadenia peregrina }(L .) \\
\text { Benth. }\end{array}$ & Angico & entre casca (chá) & asma; tosse \\
\hline Mimosa pudica $L$ & $\begin{array}{l}\text { Sensitiva; Dormideira; } \\
\text { Malícia }\end{array}$ & toda a planta & insônia \\
\hline \multicolumn{4}{|l|}{ Musaceae } \\
\hline \multirow[t]{3}{*}{ Musa spp. } & Bananeira & fruto (casca in natura) & cicatrizante \\
\hline & & pseudocaule (suco) & $\begin{array}{l}\text { antidiarréico; } \\
\text { antihemorrágico; tônico; } \\
\text { tratamento capilar }\end{array}$ \\
\hline & & fruto verde (in natura) & antidiarréico \\
\hline \multicolumn{4}{|l|}{ Myrtaceae } \\
\hline Eucaliptus spp. & Eucalipto & folhas (xarope) & $\begin{array}{l}\text { gripe; antitussígeno; } \\
\text { asma }\end{array}$ \\
\hline $\begin{array}{l}\text { Myrciaria dubia (H.B.K.) } \\
\text { McVaugh }\end{array}$ & Caçari; Camu-camu & frutos (suco) & anemia; tônico \\
\hline Psidium guajava $L$. & Goiaba & $\begin{array}{l}\text { folhas novas e brotos } \\
\text { (chá) }\end{array}$ & antidiarréico; cólicas \\
\hline \multirow[t]{2}{*}{ Punica granatum $L$. } & Romã & polpa do fruto (infusão) & diabete \\
\hline & & casca do fruto (infusão) & $\begin{array}{l}\text { inflamação na garganta; } \\
\text { antiinflamatório }\end{array}$ \\
\hline \multicolumn{4}{|l|}{ Nyctaginaceae } \\
\hline \multirow[t]{2}{*}{ Boerhavia difusa $L$. } & Pega-pinto & folhas (chá) & $\begin{array}{l}\text { malária; antinflamatório; } \\
\text { febre }\end{array}$ \\
\hline & & raíz (chá) & infecção urinária \\
\hline \multicolumn{4}{|l|}{ Oxalidaceae } \\
\hline \multirow[t]{2}{*}{ Averrhoa carambola $L$. } & Carambola & folhas (chá) & analgésico \\
\hline & & fruto (suco) & colesterol e pressão alta \\
\hline \multicolumn{4}{|l|}{ Palmae } \\
\hline \multirow[t]{3}{*}{ Cocus nucifera $L$. } & Coco & entre casca (chá) & antidiarréico; malária \\
\hline & & fibra do fruto seco (chá) & hepatite \\
\hline & & casca do fruto (chá) & anemia \\
\hline Euterpe oleracea Mart. & Açaí & raíz (chá) & anemia \\
\hline \multicolumn{4}{|l|}{ Passifloraceae } \\
\hline \multirow[t]{3}{*}{ Passiflora edulis Sims. } & Maracujá & folhas (chá) & $\begin{array}{l}\text { calmante; pressão alta; } \\
\text { fígado }\end{array}$ \\
\hline & & semente (moída) & vermífugo \\
\hline & & flor (chá) & coração \\
\hline
\end{tabular}


Tabela 1. (Continuação)

\begin{tabular}{|c|c|c|c|}
\hline Família/Nome científico & Nome popular & Parte e forma de uso & Uso medicinal \\
\hline \multicolumn{4}{|l|}{ Pedaliaceae } \\
\hline Sesamum orientale $L$. & Gergelim & semente (sumo) & $\begin{array}{l}\text { antiinflamatório; } \\
\text { pneumonia; meningite; } \\
\text { epilepsia }\end{array}$ \\
\hline \multicolumn{4}{|l|}{ Phytolaccaceae } \\
\hline Petiveria alliaceae $L$. & Tipi; Guiné & folhas & $\begin{array}{l}\text { dor de cabeça; dor de } \\
\text { dente; picada de cobra; } \\
\text { reumatismo }\end{array}$ \\
\hline \multicolumn{4}{|l|}{ Plantaginaceae } \\
\hline Plantago major L. & Trançagem & folhas (suco) & úlcera \\
\hline \multicolumn{4}{|l|}{ Portulacaceae } \\
\hline \multirow[t]{3}{*}{ Portulaca pilosa L. } & Amor crescido & folhas e raíz (suco) & $\begin{array}{l}\text { antiinflamatório; } \\
\text { cicatrizante; ouvido; } \\
\text { antimicótico }\end{array}$ \\
\hline & & folhas (chá) & laxante \\
\hline & & folhas e ramos & $\begin{array}{l}\text { queda de cabelo; fígado; } \\
\text { abortivo }\end{array}$ \\
\hline \multicolumn{4}{|l|}{ Proteaceae } \\
\hline Roupala montana Aubl. & Congonha & entre casca (chá) & antinflamatório \\
\hline \multicolumn{4}{|l|}{ Rhamnaceae } \\
\hline $\begin{array}{l}\text { Ampelozizyphus } \\
\text { amazonicus Ducke }\end{array}$ & Saracura-mirá & ramo (chá) & malária \\
\hline \multicolumn{4}{|l|}{ Rosaceae } \\
\hline Fragaria vesca $L$. & Morango & fruto in natura & diabete \\
\hline Malus domestica & Maçã & fruta in natura & diarréia \\
\hline \multicolumn{4}{|l|}{ Rubiaceae } \\
\hline \multirow[t]{2}{*}{ Genipa americana $L$. } & Jenipapo & folhas (chá) & anemia \\
\hline & & fruto in natura & diabete; antitussígeno \\
\hline \multicolumn{4}{|l|}{ Rutaceae } \\
\hline Citrus limonum L. & Limão & fruto (suco) & $\begin{array}{l}\text { gripe; gastrite; colesterol; } \\
\text { obesidade }\end{array}$ \\
\hline \multirow[t]{4}{*}{ Citrus sinensis L. Osbeck } & Laranja & frutos (suco) & gripe; gastrite; aperitivo \\
\hline & & casca do fruto & digestivo \\
\hline & & folhas (chá) & calmante \\
\hline & & semente & diabete \\
\hline Ruta graveolens $L$. & Arruda & folhas (suco, infusão) & $\begin{array}{l}\text { gastrite; cólica menstrual; } \\
\text { dor; abortivo }\end{array}$ \\
\hline \multicolumn{4}{|l|}{ Sapotaceae } \\
\hline Manilkara sp. & Massaranduba & casca (chá) & pneumonia \\
\hline \multicolumn{4}{|l|}{ Scrophulariaceae } \\
\hline \multirow[t]{2}{*}{ Scoparia dulcis $L$. } & vassourinha & folhas (chá) & diabete \\
\hline & & raíz (chá) & infecção urinária \\
\hline \multicolumn{4}{|c|}{ Simaroubaceae } \\
\hline $\begin{array}{l}\text { Geissospermum sericeum } \\
\text { (Sagot) Benth. \& Hook. }\end{array}$ & Quina-quina & casca (chá ou infusão) & $\begin{array}{l}\text { malária; abortivo; } \\
\text { contraceptivo }\end{array}$ \\
\hline Simarouba amara Aubl. & Marupá & $\begin{array}{l}\text { macerado da madeira } \\
\text { (infusão) }\end{array}$ & malária; leucemia \\
\hline
\end{tabular}


Tabela 1. (Continuação)

\begin{tabular}{|c|c|c|c|}
\hline Família/Nome científico & Nome popular & Parte e forma de uso & Uso medicinal \\
\hline \multicolumn{4}{|l|}{ Solanaceae } \\
\hline Solanum tuberosum $L$. & Batata inglesa & batata (suco) & $\begin{array}{l}\text { úlcera; vermífugo (suco } \\
\text { com casca) }\end{array}$ \\
\hline \multicolumn{4}{|l|}{ Umbelliferae } \\
\hline Daucus carota $L$. & Cenoura & raíz & $\begin{array}{l}\text { pele; cabelo; melhorar a } \\
\text { visão }\end{array}$ \\
\hline Petroselinum crispum $L$. & Salsa & raíz (chá) & icterícia \\
\hline \multicolumn{4}{|l|}{ Verbenaceae } \\
\hline Lippia microphylla Cham. & Salva do campo & folhas e ramos (chá) & $\begin{array}{l}\text { gripe; anemia; malária; } \\
\text { pneumonia; } \\
\text { antiinflamatório }\end{array}$ \\
\hline Lippia alba N.E.Br. & Erva cidreira & folhas (chá) & $\begin{array}{l}\text { calmante; vesícula; } \\
\text { antidiarréico }\end{array}$ \\
\hline \multicolumn{4}{|l|}{ Zingiberaceae } \\
\hline Curcuma longa $L$. & Açafroa & rizoma (chá) & $\begin{array}{l}\text { sarampo; catapora; } \\
\text { varíola }\end{array}$ \\
\hline Zingiber officinale Rosc. & Gengibre; Mangarataia & rizoma (xarope) & gripe \\
\hline
\end{tabular}

Esse trabalho demonstrou a importância do uso das plantas medicinais no tratamento das diversas doenças da população da cidade de Boa Vista. A combinação de plantas nativas com plantas introduzidas, hortaliças, fruteiras e outras plantas cultivadas acompanha a diversidade de costumes e cultura próprios de uma população de origem diversa, refletindo a riqueza e o potencial do conhecimento popular na cura de muitas enfermidades prevalentes na cidade de Boa Vista.

\section{LITERATURA CITADA}

AMOROZO, M.C.M. A abordagem etnobotânica na pesquisa de plantas medicinais. In: Di STASI, L.C. Plantas medicinais: arte e ciência. Um guia de estudo interdisciplinar. São Paulo: Editora da UNESP, 1996. p. 47 - 68.
BERG, M.E. van den. Plantas medicinais na Amazônia: contribuição ao seu conhecimento sistemático. Belém: Museu Paraense Emílio Goeldi, 1993. 206 p.

BRASIL, Departamento Nacional de Produção Mineral. Projeto RADAM BRASIL. Levantamento de recursos naturais. Rio de Janeiro, 1975. v. 8, 428 p.

CARRICONDE, C.; MORES, D.; FRITSCHEN, M. von; CARDOZO JÚNIOR, E.L. Plantas medicinais e plantas alimentícias. Olinda. Centro Nordestino de Medicina Popular: Universidade Federal de Pernambuco, 1996. 153 p.

CORREIA JÚNIOR, C.; MING, L.C.; SCHEFFER, M.C. Cultivo de plantas medicinais, condimentares e aromáticas. 2 ed. Jaboticabal: FUNEP, 1994. 162 p.

CRUZ, G.L. Dicionário das plantas úteis do Brasil. Rio de Janeiro: Civilização Brasileira, 1979. 599 p.
LORENZI, H. Plantas daninhas do Brasil: terrestre, aquáticas, parasitas, tóxicas e medicinais. 2 ed. Nova Odessa, SP: Editora Plantarum, 1991. 440 p.

MATOS, F.J.A.; BEZERRA, A.M.E. Plantas medicinais no Ceará - situação e perspectivas. SOB INFORMA, Curitiba,. v. XI, n. 2, v. XII, n. 1, p. $21-22,1993$.

MATTOS, J.K.A. Plantas medicinais - aspectos agronômicos. Brasília, DF., 1996, 52 p.

MILLIKEN, W. Algumas plantas usadas no tratamento de malária em Roraima. Relatório preliminar. Kew: Royal Botanical Garden, $1995.67 \mathrm{p}$.

PITHAN, O.A. Relatório Anual de Epidemiologia - 1996. Roraima: Centro de Epidemiologia de Roraima. SESAU/FNS/SEMSA, 1996. 90 p.

SCHEFFER, M.C. Roteiro para estudo de aspectos agronômicos das plantas medicinais selecionadas pela fitoterapia do SUS-PR/ CEMEPAR. SOB INFORMA, v. $x, n .2$, v. XI, n. 1. Curitiba, p. $29-31,1992$. 